\title{
Analysis of Problems and Optimization Countermeasures in the Transformation of Scientific Research Achievements in Universities
}

\section{Lu Lu}

Shen Zhen Polytechnic, Shenzhen, Guangdong, China

\begin{abstract}
In the era of the macro-knowledge economy, together with the reform of market operation mechanism, social development has become increasingly dependent on innovative technology, and it plays an important role in national strategic deployment. As the main base of scientific and technological innovation and scientific research development in our country, colleges and universities have become more diversified in their role positioning. Successful scientific research incubation will contribute to the release of their social functions and achieve self-sustainable development simultaneously. Based on the brief analysis of the problems in the transformation of scientific research achievements in colleges and universities, this article focuses on exploring the corresponding optimization strategies.
\end{abstract}

Keywords: colleges and universities; the transformation of scientific research achievements; existing problems; optimization countermeasures

\section{Introduction}

General Secretary Xi Jinping pointed out that innovation is the first driving force to lead development, and technology is a powerful weapon to overcome difficulties. As the main position for talent cultivation, the university gathers highquality intellectual teams, and is an important place for scientific research achievements to incubate. Their positioning for serving local economic development also determines the necessity of developing scientific research. In this process, the transformation of scientific research achievements in colleges and universities is a key part of its actual value output, and its related work organization research has attracted much attention.

\section{Problems in the Transformation of Scientific Research Achievements in Colleges and} Universities

In the era of knowledge economy, innovation has become the mainstream, and the progress in the field of science and technology is obvious. At the same time, Universities become an important force for the development of scientific research, due to the special talent advantages and subject advantages. Especially in the global integration pattern, it is an important means to enhance China's overall national strength by using technology to drive innovation and then promoting economic development. Thanks to the effective support of the government, the scientific research results of universities are constantly increasing, and their successful transformation into productivity is essential to highlighting the social function.

Copyright (C) 2020 by author(s) and Frontier Scientific Research Publishing Inc.

This work is licensed under the Creative Commons Attribution International License (CC BY 4.0).

http://creativecommons.org/licenses/by/4.0/ 
In a certain dimension, the transformation of scientific research achievements in colleges and universities is an important embodiment of the development concept of "science and technology are the first productive force", and it occupies an important position in the national strategic deployment. Actually, it has achieved remarkable results. However, objectively speaking, due to multiple factors, there are still many problems in the transformation of scientific research achievements in colleges and universities at this stage, and there is still much room for optimization in the future. Specifically, the work attributes and positioning of the transformation of scientific research achievements in colleges and universities determine that they serve local economic development, and the consideration of market demand is the key. However, colleges and universities have paid too much attention to the number of high-quality papers, patents, and award grades for a long time. While the scientific research achievement evaluation mechanism has rarely considered the own value and the matching degree between economic market demand. Insufficient depth of school-enterprise cooperation leads to a serious "face-saving project", resulting in a certain amount of waste of resources. At the same time, the scientific research achievements of colleges and universities have moved from laboratories to enterprises and application markets, involving multiple links of work, requiring a large amount of capital resources investment, while the strength of universities alone is obviously insufficient. It is also not easy to attract government and corporate investment for characteristics of the large investment and high risks in the transformation of scientific research achievements in colleges and universities. Many things have been shelved due to capital restrictions. The above problems are the key points that must be resolved in the transformation of scientific research achievements in universities, and there is a long way to go in the future.

\section{Optimized Countermeasures for Transformation of Scientific Research Achievements in} Colleges and Universities.

The transformation of scientific research achievements in colleges and universities is a key link to promote the actual value of scientific research achievements. As a relatively complicated systematic project, it also involves the participation of multiple stakeholders and puts forward higher requirements for the design of each link. Based on the above analysis, the author is guided by the problem and combined with the actual situation, and puts forward the following optimized countermeasures of scientific research achievements in colleges and universities for reference.

\subsection{Improve output capacity}

Colleges and universities, as the main body of transformation of scientific research achievements, the transformation of their entire working mechanism is the core. In the era of knowledge economy, based on the concept of serving local economic development, colleges and universities should correct their own positioning, from the perspective of "academictechnology-productivity", and based on the strategic deployment requirements of innovation and entrepreneurship, support the development of scientific research vigorously, and strive to create freedom and relaxation. Through a series of measures to encourage scientific research and innovation, improve output capacity, and lay the foundation for the next transformation of achievements. In this process, colleges and universities should gradually establish a scientific research management department with unified functions and powers, and separate it from other management responsibilities to form an appropriate division and relatively centralized management ecology. At the same time, it should be equipped with correspondingly perfect operating mechanisms, and clear target and task and Job requirements, in order to promote the progress of scientific research. At the same time, talents, as an indispensable intellectual resource for the transformation of scientific research achievements in colleges and universities, whose comprehensive quality and literacy level affects the effectiveness of this work directly, its professional construction is imperative. In the specific implementation process, colleges and universities should establish a high degree of talent strategy awareness, combine with their actual work needs, 
and continuously optimize the composition of the scientific research team. It can recruit talents from all over the world in a specialized and integrated manner, and establish an open talent system with fixed and mobile complementary. In addition, It should pay attention to strengthening humanistic care to strive to create a loose and free scientific research environment, organize and carry out diversified training activities to strengthen its subjective initiative awareness, share the latest achievements in scientific research to promote internal interaction, so as to burst out more creative ideas spark. Besides, colleges and universities should establish a perfect performance appraisal mechanism, get out of the strange circle of "project-thesis-awarding-title-appointment" as soon as possible, form a diversified evaluation model, and focus on the practical value of scientific research achievements. Also it should combine the actual work performance of teachers to give double rewards in spirit and material, and coordinating the distribution of benefits of scientific research results, so as to maximize their scientific research activity, and lay a solid talent base for the development of this cause.

\subsection{Deepen industry-university cooperation}

Scholar Liao Tingting believes that with the development of society and changes in the mode of knowledge production, new models of transformation of scientific research achievements are constantly changing and innovating, and the basic organizational form is industrial-university cooperation in scientific research. Therefore, deepening industryuniversity cooperation is an important starting point for promoting the transformation and optimization of scientific research achievements in colleges and universities, and it largely solves the problem that scientific research achievements are not practical. In fact, under the operation of the market economy system, and in the face of fierce competition challenges, the requirements for the transformation of scientific research results are becoming higher and higher, which requires a large amount of human, material and financial support, thus it is difficult to complete simply by universities or enterprises. And only by combining the advantages of the two can we achieve a mutually beneficial and win-win situation. In the specific implementation process, colleges and universities should actively respond to the national strategic call, meet the needs of local economic development initiatively, guide the direction of scientific research, fully integrate their own disciplinary advantages, integrate and allocate all kinds of resources, establish different models of scientific research centers and innovation alliances, promote the output of innovative results, and help companies improve their overall competitiveness, thus get more support from companies. At the same time, for enterprises, it is also necessary to actively participate in the transformation of scientific research achievements in universities based on the strategic considerations of sustainable development, and strengthen the dialogue with the government and universities, give full play to their own market advantages, provide important data and information support for university research, and improve its practicality, in order to win the recognition and favor of the market, and extract the own profit from it, and work together to create a benign industrial-academic circulation system. In addition, local governments also need to pay close attention to the development of scientific research undertakings in colleges and universities, deeply understand their strategic significance, conduct in-depth practical investigation, find the difficulties faced by them, increase macro-control efforts, and guide the establishment of " The "Trinity of Government, Schools and Enterprises" scientific research transformation model, and gradually improve the support of related basic supporting facilities, including service platforms, standard systems, etc., help to improve the transformation rate of scientific research achievements in colleges and universities, thereby vigorously promote the upgrading of regional industrial structure and achieve local economic take-off.

\subsection{Increase funding guarantee}

From the incubation to the transformation of scientific research achievements in universities, they need to go through many links such as basic research, technology development, achievement transformation, and market launch, and finally realize their application value. They have the characteristics of time-consuming, high risk, and require large capital 
investment. However, the colleges and universities are unable to afford it, which is the key factor restricting the progress of this work. In fact, under the guidance of the strategy of rejuvenating the country through science and education, the local government's support for the research and development of universities has been continuously strengthened, but there are huge funds in the overall urban development and deployment. Therefore, it is unable to cover the transformation of scientific research achievements in universities from start to finish, which results in a capital chain the problem of faults. In this regard, based on the macroeconomic environment of the economic market, the government can issue a series of preferential policies to encourage innovation in financial services, combine the particularity of the transformation of scientific research achievements in universities, enrich the types of financial product structures, and expand the process of industrialization and commercialization of scientific research achievements in universities financial support. At the same time, colleges and universities also need to escape from the inherent thinking pattern as soon as possible, and face the broader economic market, increase the publicity of immediate scientific research achievements, and demonstrate their own strength, in order to attract financial institutions, private capital and enterprises to invest, and forming a diversified financial support system for transformation of scientific research achievements, improving the output efficiency of scientific research achievements, draining social capital is conducive to the realization of the strategic goal of "science and education rejuvenates the country" while reducing government financial pressure. In this process, we closely rely on industry-university cooperation, integrate enterprise development resources, work together to build a research base in the school, give full play to our own intellectual team advantages, and develop together with enterprises. On this basis, with the accumulation of time, the allocation of funds in the transformation of scientific research achievements in colleges and universities has become more abundant. It is necessary to strengthen the construction of the supervision system, ensure that special funds are used exclusively, strictly implement the responsibility system, refine the investment of various projects, and pay attention to the inspection work. safeguarding the rights of various stakeholders and ensuring the fairness and openness of the whole process to enhance the investment confidence of social capital, which is the only way to promote the sustainable development of this work.

\subsection{Improve service system}

In a certain dimension, the key to the transformation of scientific research achievements in colleges and universities lies in marketization. In this process, as an effective means, scientific and technological intermediary services play a significant role in promoting their commercialization and industrialization. In fact, based on the stimulating effect of market demand, technology intermediary services are constantly increasing, and are gradually moving towards specialization and scalization, but at the same time, due to the trend of interest, some vicious competitive behaviors have appeared, hindering the release of their functions. Under the strategic perspective of comprehensive rule of law, in order to further promote the transformation of scientific research achievements in colleges and universities, while vigorously supporting the development of science and technology intermediary service institutions, it is also necessary to strengthen relevant supervision, gradually improve relevant policies and regulations, clarify their legal status and rights status, and straighten out the relationship with the government, and regulate the order of market behavior and make it shine in the field of transformation of scientific research achievements in universities. At the same time, complete technology intermediary services should include technology transfer, achievement transformation and industrialization services, etc. And it should fully penetrate into the technological innovation system structure, and complement each other through intermediary services such as investment and financing institutions, legal affairs, accounting affairs, asset evaluation, in order to provide comprehensive and professional support for the transformation of scientific research achievements in universities and improve their work efficiency, which is an important direction for the future development of this cause. In addition, under 
the macro-economy era, Internet applications have further accelerated the flow of information, and are more convenient and efficient, which is the basic condition for promoting the docking and interaction of scientific and technological innovation elements. Based on this, It is an inevitable trend of the development of the current era to accelerate the construction of a platform for the transformation of scientific research achievements in universities, organically bring together various intermediary services, and open up interactive channels between universities and enterprises to form a comprehensive, diversified, full-process, and integrated information data network to provide support for the entire process of scientific research innovation and achievement incubation in colleges and universities, which can effectively reduce related cost investment and improve the practicality of scientific research.

\section{Conclusions}

All in all, the transformation of scientific research achievements in colleges and universities is very important and necessary. As a relatively complicated systematic project, we should pay attention to the optimization of each link in practice, rely on industry-university cooperation, and improve the output capacity of scientific research achievements. Pay attention to its practical value construction, and gather multiple forces to support and increase capital guarantee. And improve the relevant service system at the same time, so as to better serve the local economic development and achieve the national strategic goal of "national rejuvenation through science and education".

\section{Conflicts of Interest}

The author declares no conflicts of interest regarding the publication of this paper.

\section{References}

[1] Yu X.T. (2020). Briefly Describe the Problems and Countermeasures in the Transformation of Scientific Research Achievements in Colleges and Universities, Science and Technology Information, 18(12): 217-218.

[2] Yang Z.M. (2020). Centering on the Cooperation Between Schools and Enterprises to Actively Promote the Transformation of the Achievements of Higher Education and Scientific Research, Think Tank Era, (10): 217-218.

[3] He H.B., Zou K., Yang C.Y. and Luo H.J. (2020). the Status Quo and Countermeasures of the Transformation of Scientific and Technological Achievements of Chinese Universities under the New Situation, Heilongjiang Science, 11(05): 159-161.

[4] Wan N., Nie Y.R., Pan L.L. and Wu Y.F. (2020). Exploration on the Mode of Promoting the Transfer and Transformation of Scientific Research Achievements in Universities_-Taking Jiangxi University of Traditional Chinese Medicine as an Example, Think Tank Era, (05): 64-65.

[5] Jin H. (2019). Construction of Realization Mechanism for Transformation of Scientific Research Achievements in Universities, China University Science and Technology, (12): 87-89. 